Revue d'histoire de l'Amérique française

REVUE D.HISTOIRE DE L'AMÉRIQUE FRANÇAISE

MITCHELL, Estelle, Les Soeurs Grises de Montréal à la Rivière-Rouge, 1844-1984. Montréal, Éditions du Méridien, 1987. $19,95 \$$

\title{
Jacqueline Blay
}

Volume 42, numéro 1, été 1988

URI : https://id.erudit.org/iderudit/304670ar

DOI : https://doi.org/10.7202/304670ar

Aller au sommaire du numéro

Éditeur(s)

Institut d'histoire de l'Amérique française

ISSN

0035-2357 (imprimé)

1492-1383 (numérique)

Découvrir la revue

Citer ce compte rendu

Blay, J. (1988). Compte rendu de [MITCHELL, Estelle, Les Soeurs Grises de Montréal à la Rivière-Rouge, 1844-1984. Montréal, Éditions du Méridien, 1987. 19,95 \$]. Revue d'histoire de l'Amérique française, 42(1), 125-127.

https://doi.org/10.7202/304670ar d'utilisation que vous pouvez consulter en ligne.

https://apropos.erudit.org/fr/usagers/politique-dutilisation/ 


\section{NOTES BIBLIOGRAPHIQUES}

MITCHELL, Estelle, Les Soeurs Grises de Montréal à la Rivière-Rouge, 18441984. Montréal, Éditions du Méridien, 1987. 19,95\$

L'Ordre des Soeurs Grises de Montréal a tout récemment fêté son 250e anniversaire de fondation. Congrégation dévouée tout d'abord aux oeuvres de 
charité, les Soeurs Grises sont synonymes au 20e siècle d'engagement dans toute oeuvre de type social. Leur présence est reconnue, sinon recherchée, dans les milieux hospitaliers et les services d'aide aux personnes handicapées mentalement ou physiquement. L'Ordre des Soeurs Grises, de par la vocation imposée par sa fondatrice, Marguerite d'Youville, a su donner, très tôt, une ampleur et une profondeur à son apostolat.

Presqu'un siècle après la fondation de l'Ordre, les religieuses reçoivent une demande bien spécifique de la part de Mgr Provencher, évêque à la RivièreRouge et ayant grand besoin d'aide. Après 25 ans de recherches, il sollicite et obtient «trois religieuses pour assurer l'enseignement chrétien et initier la jeunesse féminine aux arts domestiques» (p. 18). Les missions des Soeurs Grises dans l'Ouest commenceront ainsi et, depuis 1844, elles n'ont pas cessé de porter la parole de l'Évangile aux malades et aux déshérités, fondant sur leur passage des hôpitaux, des cliniques, des écoles aux pays d'En Haut.

Lorsqu'une institution ou une congrégation aussi imposante continue, 250 ans après sa fondation, à avoir au sein de la société une place tout aussi respectable qu'à ses débuts, il est souhaitable de voir les historiens se pencher sur son histoire et écrire l'ouvrage définitif qui permettra de faire découvrir pleinement un tel sujet. Les Soeurs Grises de Montréal à la Rivière-Rouge, 1844-1984 d'Estelle Mitchell aux Éditions du Méridien n'est malheureusement pas l'ouvrage qui saura soulever l'enthousiasme et intéresser les historiens.

Les intentions sont bonnes cependant. Estelle Mitchell campe, dans le premier chapitre, un portrait rapide de Mgr Provencher. S'il est court, il n'en a pas moins une dimension à la hauteur de son personnage. Très rapidement, par contre, les noms et les visages qui viennent au-devant du lecteur passent trop vite et deviennent une succession de noms et de dates. En dépit de toute l'attention et de tout l'intérêt portés à ce genre de sujets et à l'Ouest en général, le lecteur, même bienveillant, ne pourra s'empêcher de chercher ce quelque chose de plus qui a inspiré tant de religieuses à quitter une province natale civilisée pour une nature aussi hostile et inculte. L'historien cherchera, en vain, un contexte, une toile de fond, qui pourraient illustrer les motivations des Soeurs Grises à s'exiler. La foi en Dieu, toujours présente au cours du récit, n'explique pas tout pour qui cherche un reflet de la réalité qui attendait les religieuses dans leurs entreprises de charité, ou encore dans l'établissement d'institutions scolaires. Par exemple, on cherche, en vain, une évaluation des conséquences des lois néfastes de 1890 sur les priorités de l'ordre missionnaire.

Les Soeurs Grises de Montréal à la Rivière-Rouge, 1844-1984, n'est donc pas l'ouvrage qui nous fera découvrir, sans contredit, cette congrégation religieuse. Il y a peut-être deux explications possibles à ces lacunes. La première réside dans l'approche prise par l'auteure, une approche chronologique plutôt que thématique. Les chapitres portent des dates plutôt que des titres. Résultat, on avance dans le temps, sans jamais avoir le bénéfice d'une vue d'ensemble ou d'une analyse quelconque. Les événements ou les faits sont reliés par le fil des dates sans le support du contexte historique. D'autre part, l'ouvrage devait être rédigé par Soeur Élizabeth de Moissac, historienne bien connue de la communauté franco-manitobaine et qui avait, dès 1972, commencé à travailler 
sur le projet. Le temps lui a fait défaut et Soeur Estelle Mitchell a dû prendre la relève et c'est là la deuxième explication aux lacunes majeures de cet ouvrage. Quiconque a pris la relève d'un collègue sait combien le défi est grand et ne peut pas parfois être relevé.

Il faut donc regretter que cet ouvrage ne soit pas meilleur, plus solide sur le plan des références ou de l'ensemble. Il faut louer la tentative et espérer que l'ouvrage sera remis sur le métier, un jour ou l'autre, pour rendre vraiment hommage aux Soeurs Grises de Montréal à la Rivière-Rouge.

JACQUELINE BLAY 